\title{
Evaluation of Anemia among Patients with End Stage Renal Disease on Hemodialysis in Al-Gharbia Governorate
}

\author{
AHMED M.A. FAHMY, M.Sc.*; GAMAL F. EL-NAGGAR, M.D.*; GHADA M. AL-GHAZALY, M.D.* and \\ MOHAMED A. SAAD, M.D.** \\ The Departments of Internal Medicine* and Clinical Pathology**, Faculty of Medicine, Tanta University, Tanta, Egypt
}

\begin{abstract}
Background: Chronic Kidney Disease (CKD) is a major health problem and its prevelence is increasing worldwide. Chronic kidney disease results in complex endocrinal and metabolic alterations. Anemia is a common complication of chronic kidney disease. There are various causes of anemia in chronic kidney disease patients on hemodialysis like malnutrition, infection, inflammation and hyperparathyroidism.

Aim of Work: The aim of the present work is to evaluate anemia among patients with ESRD on regular hemodialysis in Al-Gharbia governorate.

Patients and Methods: The study was done on 400 patients with ESRD on regular hemodialysis in more than one center for HD in Al-Gharbia governorate. All patients in this study were subjected to: History taking, full clinical examination, laboratory investigations done were intact Complete Blood Count (CBC), parathyroid hormone, serum phosphorus, ionized calcium, serum ferritin, transferrin saturation, serum albumin and $\mathrm{C}$ reactive protein after obtaining an informed consent.

Results: There was significant negative correlation between $\mathrm{Hb}$ and reticulocytic count $(p=0.003 *)$, there was significant negative correlation between $\mathrm{Hb}$ and PTH $(p=0.001 *)$, there was significant negative correlation between $\mathrm{Hb}$ and $\mathrm{S}$.albumin $\left(p=0.019^{*}\right)$, there was significant negative correlation between $\mathrm{Hb}$ and $\mathrm{CRP}\left(p=0.011^{*}\right)$ there was positive significant correlation between $\mathrm{Hb}$ and $\mathrm{T}$.Sat. $\left(p=0.038^{*}\right), \mathrm{Hb}$ showed no significant correlation with serum ferritin, ionized calcium and phosphorus.
\end{abstract}

In Conclusion: Our finding suggests that many factors affect anemia in patients with ESRD on regular hemodialysis these factors include malnutrition, inflammation, iron deficiency and hyperparathyroidism.

Key Words: Chronic Kidney Disease (CKD) - Hemodialysis - Anemia - Malnutrition - Infection - Inflammation-Hyperparathyroidism.

Correspondence to: Dr. Ahmed M.A. Fahmy,

The Department of Internal Medicine, Faculty of Medicine, Tanta University, Tanta, Egypt

\section{Introduction}

CHRONIC kidney disease is a very real and growing problem. The total number of treated patients has markedly increased during the last 30 years [1]. CKD is defined as abnormalities of kidney structure or function (defined by markers of kidney injury or decreased Glomerular Filtration Rate (GFR) present for $>3$ month [2]

Anemia commonly occurs in people with Chronic Kidney Disease (CKD) either with permanent or partial loss of kidney function. Anemia might begin to develop in the early stages of CKD, when someone has 20 to 50 percent of normal kidney function. Anemia tends to worsen as CKD progresses [3].

Erythropoietin deficiency appears to be the major cause of anemia in chronic kidney disease [4]. Serum erythropoietin level in CKD patients does not increase exponentially when hemoglobin concentration declines as compared to healthy persons [5]. Anemia of CKD is characterized by a relative deficiency of erythropoietin, because the serum erythropoietin level is inappropriately low for the degree of anemia this type of anemia is characterised by normochromic and normocytic blood cells, and hypoplasia of erythroid cells [6]

There are various causes of anemia in chronic kidney disease patients on hemodialysis. Iron deficiency is also common in patients with Chronic Kidney Disease (CKD) [7] . The iron deficiency may be absolute, often due to poor dietary intake or sometimes occult bleeding, or functional, when there is an imbalance between the iron requirements of the erythroid marrow and the actual iron supply. Iron deficiency leads to a reduction in formation of red cell hemoglobin, causing hypochromic mi- 
crocytic anemia. Other causes for anemia in chronic kidney disease include the presence of uremic inhibitors (e.g, parathyroid hormone, inflammatory cytokines), reduced half-life of circulating blood cells and deficiencies of folate or vitamin B12 [7]

Anemia is diagnosed in adults with CKD when the $\mathrm{Hb}$ concentration is $<13.0 \mathrm{~g} / \mathrm{dl}(<130 \mathrm{~g} / \mathrm{l})$ in males and $<12.0 \mathrm{~g} / \mathrm{dl}(<120 \mathrm{~g} / \mathrm{l})$ in females [8]

The clinical consequences of anemia depend on the severity of the reduction in arterial oxygen concentration and the adaptive capacity to this change. There is increasing evidence that the presence of renal failure alters the adaptive capacity to anemia in several ways [9].

Suppression of erythropoiesis occurs during severe infectious processes, inflammatory diseases, and malignancies. Inflammation is often accompanied by malnutrition and both have a significant role in the development of anemia [10]

Severe hypoalbuminemia is associated with a significant impairment of the erythropoietic response. A link between malnutrition and anemia can be attributed to the malnutrition inflammation anemia complex syndrome (MIA syndrome) [11].

\section{Subjects and Methods}

This study was carried out on 400 subjects selected from multiple centers for hemodialysis in Al-Gharbia Governorate from February 2016 to July 2016, after obtaining their informed consent and within the approved ethical protocol of Faculty of Medicine.

All participant names were hidden and replaced by code numbers to maintain privacy of the patients.

Study design: Cross-sectional study.

Study approval: Permission obtained from Research Ethics Committee as a part of Quality Assurance Unit in Faculty of Medicine at Tanta University to conduct this study and to use the facilities in the hospital. Informed written consent was obtained from all patients after full explanation of benefits and risks of the study. Privacy of all patients' data is granted by a special code number for every patient file that includes all investigations.

Inclusion criteria: Patients with ESRD on regular hemodialysis for more than 3 months.

Exclusion criteria: Patients on Hemodialysis less than 3 months.
Methods: All cases included in the study were subjected to the following after obtaining an informed consent:

Full history taking: Regarding age, sex, residence, presentation, past medical history, any previous medical treatment if present, period of $\mathrm{HD}$, place of HD and number of sessions per week.

Complete clinical examination: Examination for hepatomegaly, splenomegaly and examination of renal angles.

Laboratory investigations including: Complete Blood Count (CBC) which should include ( $\mathrm{Hb}$ concentration, red cell indices, total and differential white blood cell count, and platelet count), serum Ferritin, Transferrin saturation (T.SAT), serum albumin, C-Reactive Protein (CRP), Parathyroid Hormone (PTH), Ionized Calcium and Phosphorus.

Blood sampling and processing: Under quality control and safety procedure for sample collection, $10 \mathrm{ml}$ venous blood sample was collected in plain vaccutainer tubes after 6 hours fasting. $2 \mathrm{~cm}$ were added to EDTA for CBC. Serum was separated from the other $8 \mathrm{~cm}$ blood for all specimens using fine centrifugation at $3000 \mathrm{rpm}$ for $15 \mathrm{~min}$. Serum samples were sent to the lab within 2 hours of collection, for analysis. Serum samples were assayed for Serum Ferritin, T.saturation, CRP, Serum Albumin, Ionized Calcium, Phosphorus and PTH levels.

\section{Results}

Our study was done on 400 patients known to be ESRD on regular HD (184 males-216 females) their age ranged from 16 to 85 years with a mean age $(52.23 \pm 15.37)$ years.

Our study included 184 males (46\%) and 216 females (54\%). (Table 1) \& Fig. (1):

Table (1): Classification of the patients according to gender.

\begin{tabular}{lcl}
\hline Sex & N & $\%$ \\
\hline Male & 184 & 46 \\
Female & 216 & 54 \\
\hline Total & 400 & 100 \\
\hline
\end{tabular}

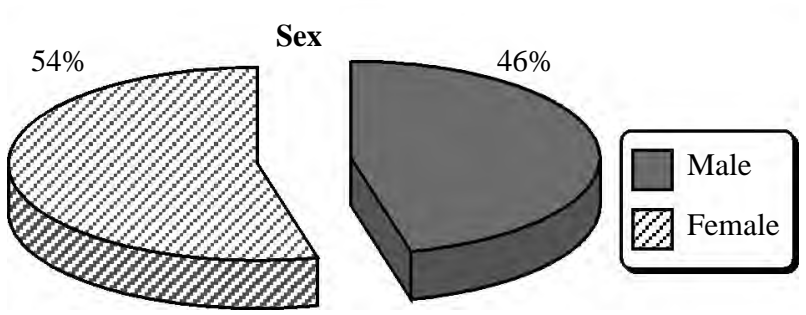

Fig. (1): Classification of the patients according to gender. 
The age ranged from 16 to 85 years with a mean age (52.23 \pm 15.37$)$ years (Table 2$)$ :

Table (2): Range of the age in between patients of the study.

\begin{tabular}{ccc}
\hline & Range & Mean \pm S.D \\
\hline Age & $16-85$ & $52.23 \pm 15.37$ \\
\hline
\end{tabular}

Our study include $142 \mathrm{HCV}$ positive (35.5\%) and 258 negative (64.5\%) (Table 3 ) \& Fig. (2):

Table (3): Classification of the patients according to virology.

\begin{tabular}{lcc}
\hline Virology & $\mathrm{N}$ & $\%$ \\
\hline HCV positive & 142 & 35.5 \\
Negative & 258 & 64.5 \\
\hline Total & 400 & 100 \\
\hline
\end{tabular}

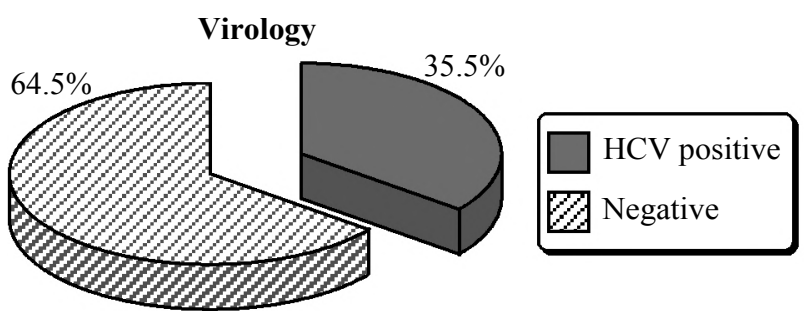

Fig. (2): Classification of the patients according to virology.

Our study show that hypertension is the commonest cause 231 patients $(57.75 \%)$, DM 121 patients $(30.25 \%)$, obstructive uropathy 68 patients (17\%), glomerulonephritis 45 patients $(11.25 \%)$, congenital 20 patients $(5 \%)$, multiple myeloma 5 patients (1.25\%) (Table 4) \& Fig. (3):

Table (4): Classification of the patients according to causes of ESRD.

\begin{tabular}{lll}
\hline Causes & $\mathrm{N}$ & $\%$ \\
\hline HTN & 231 & 57.75 \\
DM & 121 & 30.25 \\
Ob. Urop. & 68 & 17 \\
GN & 45 & 11.25 \\
Congenital & 20 & 5 \\
M. Myeloma & 5 & 1.25 \\
\hline Total & 400 & 100 \\
\hline
\end{tabular}

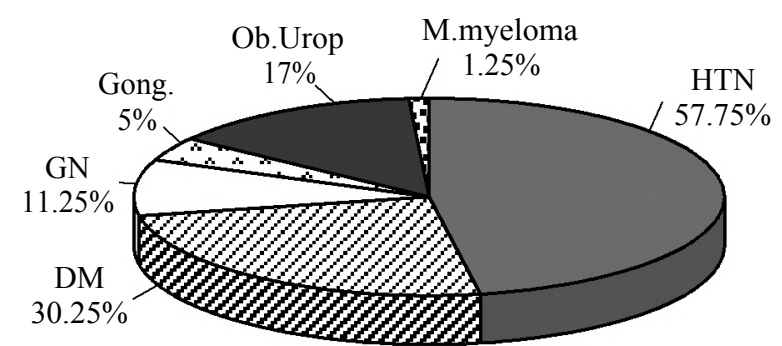

Fig. (3): Classification of the patients according to causes of ESRD.
Our study show that 272 patients $(68 \%)$ were normocytic while 128 patients $(32 \%)$ were microcytic (Table 5) \& Fig. (4).

Table (5): Classification of the patients according to MCV.

\begin{tabular}{lcc}
\hline MCV & $\mathrm{N}$ & $\%$ \\
\hline Normocytic & 272 & 68 \\
Microcytic & 128 & 32 \\
\hline Total & 400 & 100 \\
\hline
\end{tabular}

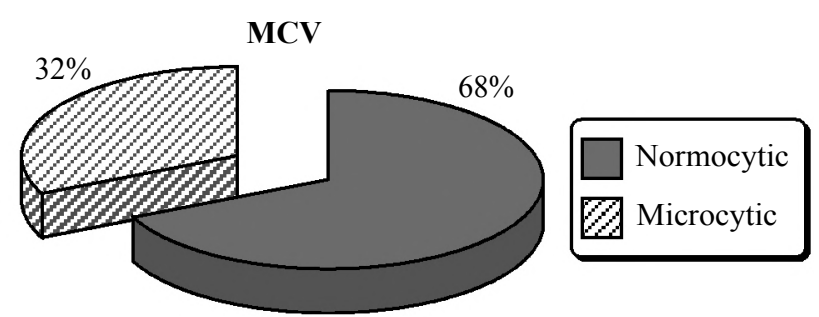

Fig. (4): Classification of the patients according to MCV.

Our study show that 262 patients $(65.5 \%)$ were normochromic, while 138 patients $(34.5 \%)$ were hypochromic (Table 6) \& Fig. (5).

Table (6): Classification of the patients according to $\mathrm{MCH}$.

\begin{tabular}{lcc}
\hline $\mathrm{MCH}$ & $\mathrm{N}$ & $\%$ \\
\hline Normochromic & 262 & 65.5 \\
Hypochromic & 138 & 34.5 \\
\hline Total & 400 & 100 \\
\hline
\end{tabular}

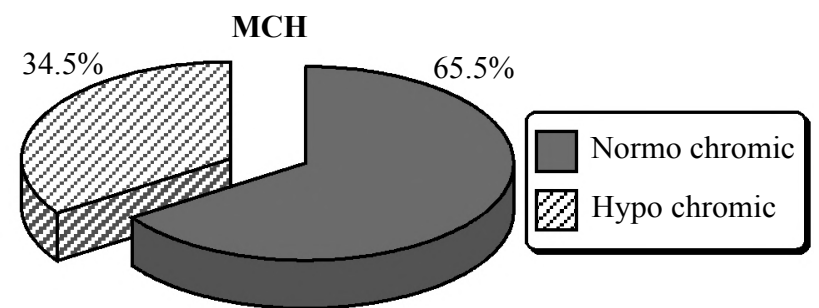

Fig. (5): Classification of the patients according to $\mathrm{MCH}$.

Our study show that 270 patients $(69.7 \%)$ were normocytic normochromic anemia while, 121 patients $(30.3 \%)$ were microcytic hypochromic anemia (Table 7) \& Fig. (6).

Table (7): Classification of the patients according to type of Anemia.

\begin{tabular}{lcc}
\hline Type of anemia & $\mathrm{N}$ & $\%$ \\
\hline NNA & 279 & 69.7 \\
HMA & 121 & 30.3 \\
\hline Total & 400 & 100 \\
\hline
\end{tabular}




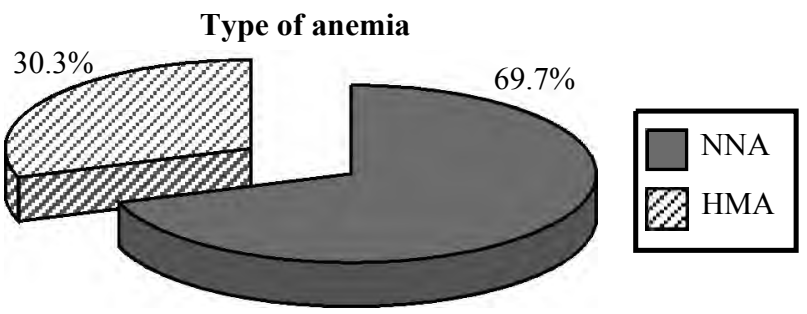

Fig. (6): Classification of the patients according to type of Anemia.

Our study show that 341 patients $(85.25 \%)$ were showing reticulocytosis, while 59 patients $(14.75 \%)$ were normal reticulocytic count (Table 8) \& Fig. (7).

Table (8): Classification of the patients according to Retic.count.

\begin{tabular}{lll}
\hline Retic. count & $\mathrm{N}$ & $\%$ \\
\hline Normal & 59 & 14.75 \\
Reticulocytosis & 341 & 85.25 \\
\hline Total & 400 & 100 \\
\hline
\end{tabular}

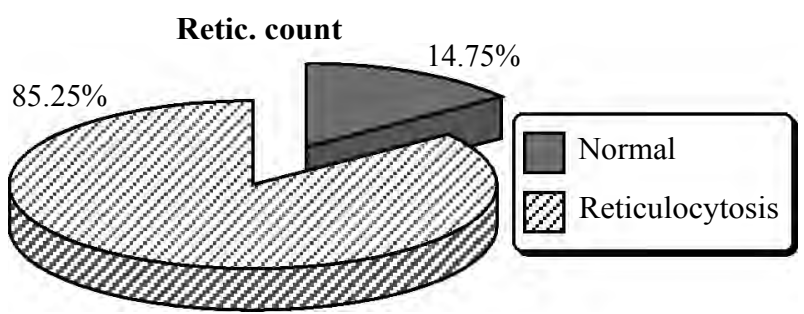

Fig. (7): Classification of the patients according to Retic.count.

Our study show that 204 patients $(51 \%)$ were showing decreased T.sat. while, 196 patients $(49 \%)$ were normal T.sat. (Table 9) \& Fig. (8).

Table (9): Classification of the patients according to T. sat.

\begin{tabular}{lcc}
\hline T. sat & N & $\%$ \\
\hline Normal & 196 & 49 \\
Decreased & 204 & 51 \\
\hline Total & 400 & 100 \\
\hline
\end{tabular}

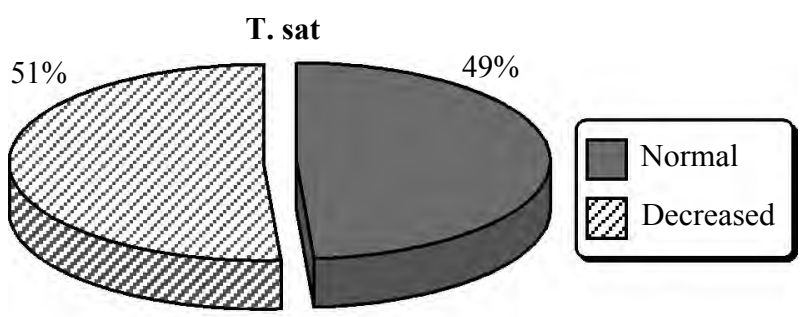

Fig. (8): Classification of the patients according to T. sat.
Our study show that 247 patients $(56.75 \%)$ were normal ferritin level while, 151 patients (37.75\%) show high ferritin level, 22 patients (5.5\%) show low ferritin level (Table 10) \& Fig. (9)

Table (10): Classification of the patients according to ferritin.

\begin{tabular}{lll}
\hline S. ferritin & $\mathrm{N}$ & $\%$ \\
\hline Normal & 247 & 56.75 \\
High & 151 & 37.75 \\
Low & 22 & 5.5 \\
\hline Total & 400 & 100 \\
\hline
\end{tabular}

\section{S. ferritin}

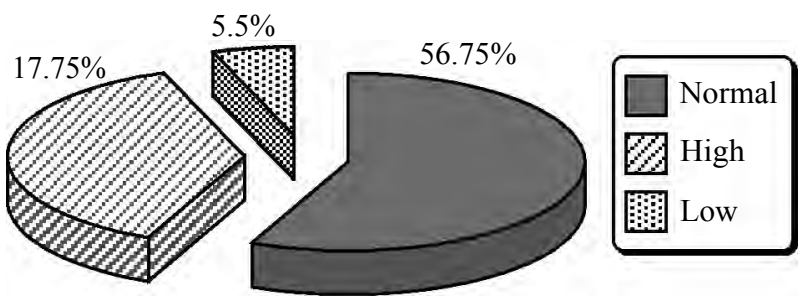

Fig. (9): Classification of the patients according to ferritin.

Our study show that 243 patients $(60.8 \%)$ show hypocalcaemia, while 144 patients $(36 \%)$ show normal calcium level, 13 patients $(3.2 \%)$ show hypercalcimia (Table 11) \& Fig. (10).

Table (11): Classification of the patients according to Ionized calcium.

\begin{tabular}{lll}
\hline I. Ca & $\mathrm{N}$ & $\%$ \\
\hline Normal & 144 & 36 \\
High & 13 & 3.2 \\
Low & 243 & 60.8 \\
\hline Total & 400 & 100 \\
\hline
\end{tabular}

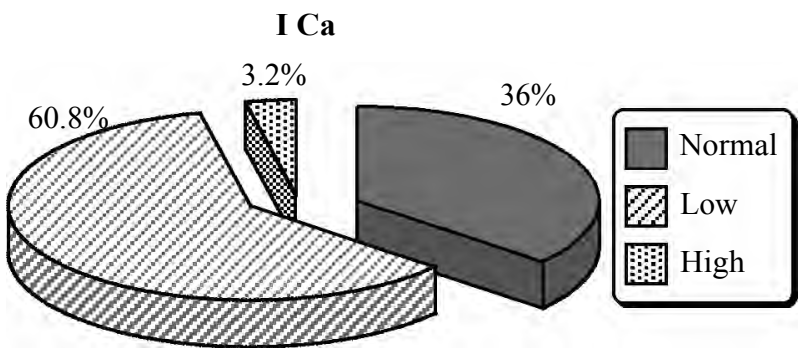

Fig. (10): Classification of the patients according to Ionized calcium.

Our study show 284 patients (71\%) with high phosphorus level while, 116 patients $(29 \%)$ show normal phosphorus level (Table 12) \& Fig. (11). 
Table (12): Classification of the patients according to Phosphorus.

\begin{tabular}{lcc}
\hline Phosphorus & $\mathrm{N}$ & $\%$ \\
\hline Normal & 116 & 29 \\
High & 284 & 71 \\
\hline Total & 400 & 100 \\
\hline
\end{tabular}

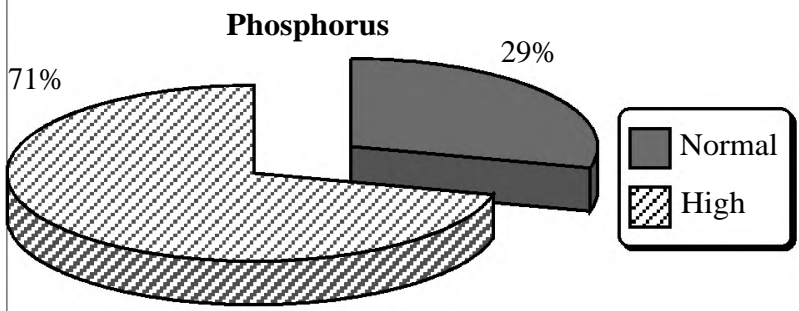

Fig. (11): Classification of the patients according to Phosphorus.

Our study show 374 patients (93.5\%) with hyperparathyroidism while, 22 patients $(5.5 \%)$ with normal PTH and 4 patients (1\%) with hypoparathyroidism (Table 13) \& Fig. (12).

Table (13): Classification of the patients according to PTH.

\begin{tabular}{lll}
\hline PTH & $\mathrm{N}$ & $\%$ \\
\hline Normal & 22 & 5.5 \\
High & 374 & 93.5 \\
Low & 4 & 1 \\
\hline Total & 400 & 100 \\
\hline
\end{tabular}

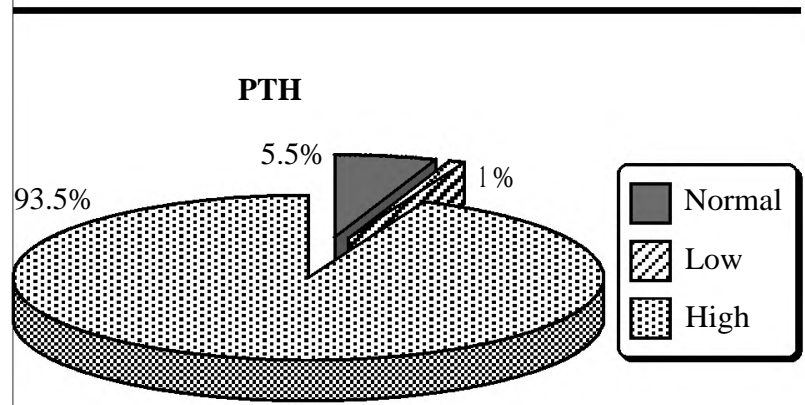

Fig. (12): Classification of the patients according to PTH.

Our study show 214 patients $(53.5 \%)$ with hypoalbuminemia while, 186 patients $(46.5 \%)$ with normal albumin level (Table 14) \& Fig. (13).

Table (14): Classification of the patients according to S. Albumin.

\begin{tabular}{lll}
\hline S. Alb & N & $\%$ \\
\hline Normal & 186 & 46.5 \\
Low & 214 & 53.5 \\
\hline Total & 400 & 100 \\
\hline
\end{tabular}

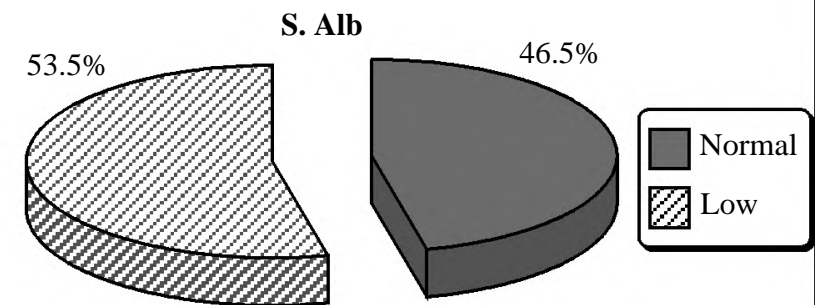

Fig. (13): Classification of the patients according to S. Albumin.

Our study show 213 patients $(53.2 \%)$ with high CRP level while, 187 patients $(46.8 \%)$ with normal CRP level (Table 15) \& Fig. (14).

Table (15): Classification of the patients according to CRP.

\begin{tabular}{llc}
\hline CRP & $\mathrm{N}$ & $\%$ \\
\hline Normal & 187 & 46.8 \\
High & 213 & 53.2 \\
\hline Total & 400 & 100 \\
\hline
\end{tabular}

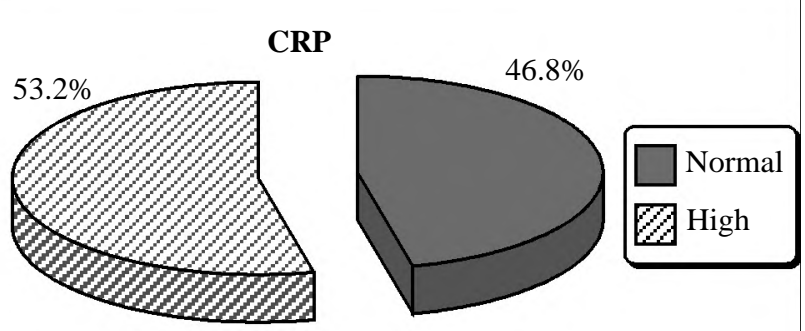

Fig. (14): Classification of the patients according to CRP.

Table (16): Correlation between Hb level and different laboratory parameters.

\begin{tabular}{|c|c|c|}
\hline & \multicolumn{2}{|c|}{$\mathrm{Hb}$} \\
\hline & $r$ & $p$-value \\
\hline Retic. Count & -0.486 & $0.003 *$ \\
\hline T. sat & 0.104 & $0.038^{*}$ \\
\hline S. ferritin & 0.043 & 0.389 \\
\hline I. $\mathrm{Ca}$ & 0.043 & 0.388 \\
\hline Phosphorus & -0.017 & 0.734 \\
\hline PTH & -0.605 & $0.001 *$ \\
\hline S. Alb & -0.649 & $0.019 *$ \\
\hline CRP & -0.307 & $0.011^{*}$ \\
\hline
\end{tabular}

*: Significant $(p<0.05) . \quad r$ : Pearson's correlation coefficient.

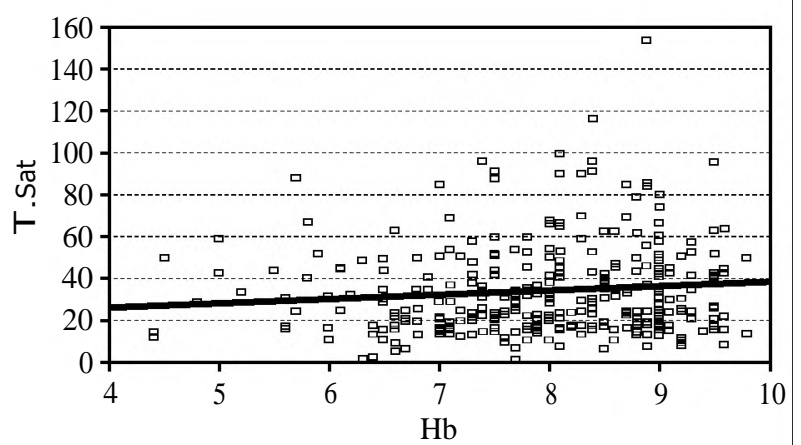

Fig. (15): Correlation between $\mathrm{Hb}$ and T. Sat. Positive significant correlation between $\mathrm{Hb}$ and T. Sat ( $r=0.104$, $p=0.038^{*}$ ), 


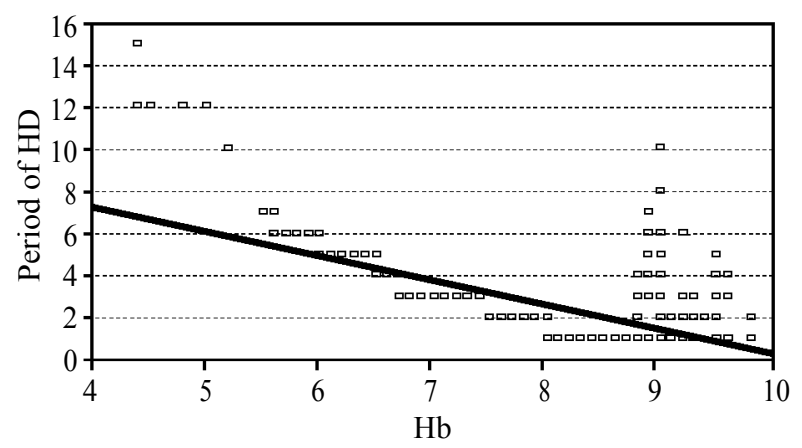

Fig. (16): Correlation between $\mathrm{Hb}$ and period of HD. Significant negative correlation between $\mathrm{Hb}$ and period of HD $(r=0.606, p=0.021 *)$.

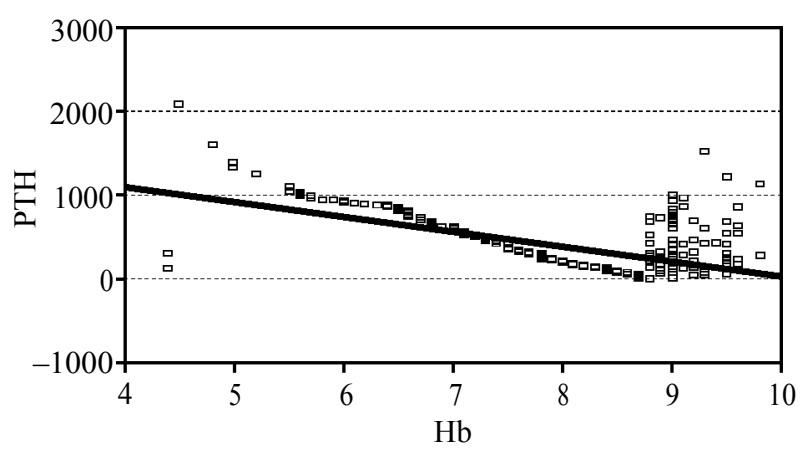

Fig. (17): Correlation between $\mathrm{Hb}$ and PTH. Significant negative correlation between $\mathrm{Hb}$ and PTH $(r=$ $-0.605, p=0.001 *)$

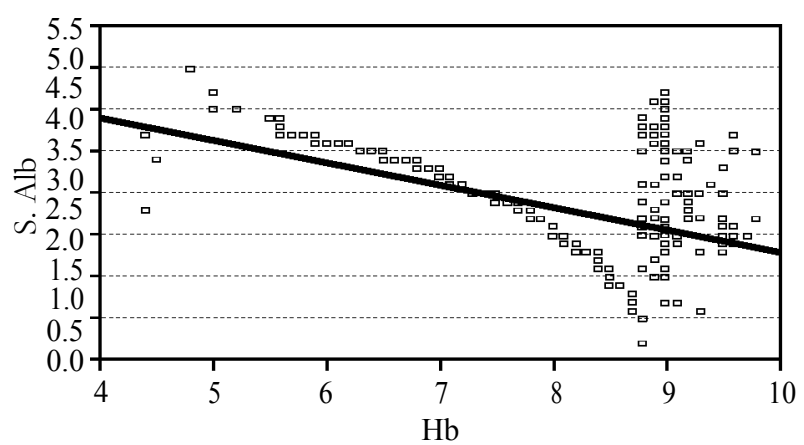

Fig. (18): Correlation between $\mathrm{Hb}$ and S.albumin. Significant negative correlation between $\mathrm{Hb}$ and $\mathrm{S}$.albumin $\left(r=0.649, p=0.019^{*}\right)$.

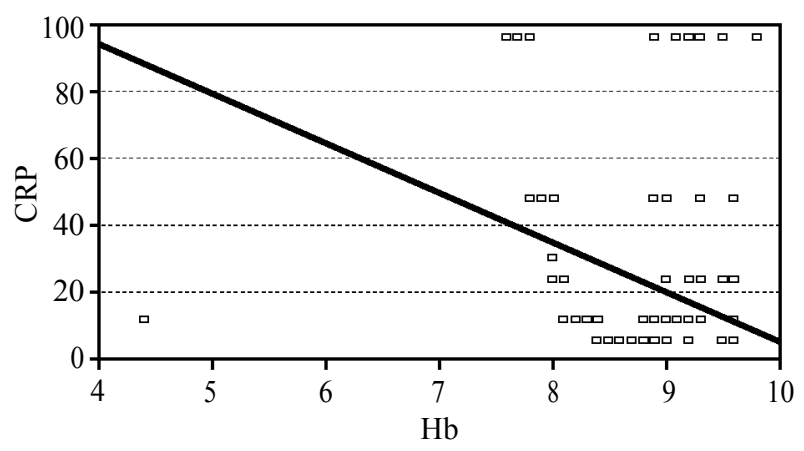

Fig. (19): Correlation between Hb and CRP. Significant negative correlation between $\mathrm{Hb}$ and CRP ( $r=$ $-0.307, p=0.011 *$ ).

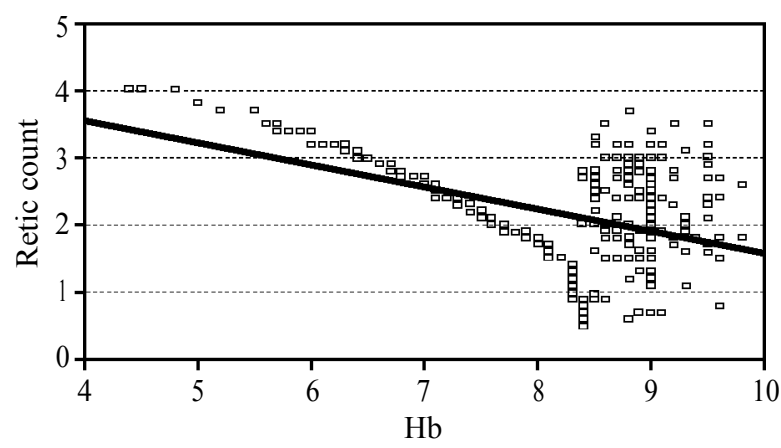

Fig. (20): Correlation between $\mathrm{Hb}$ and reticulocytic count. Significant negative correlation between $\mathrm{Hb}$ and reticulocytic count $(r=-0.486, p=0.003 *)$.

\section{Discussion}

The present study was in order to evaluate anemia in patients with ESRD on regular HD and to find out the correlation between anemia and the risk factors that may affect it in those patients like malnutrition, infection, inflammation and hyperparathyroidism in 400 patients on regular HD in multiple centers for $\mathrm{HD}$ in $\mathrm{Al}$ Gharbia governorate.

In the present study, females represented 54\% and males represented $46 \%$ of patients with ESRD. The present study showed that ESRD is common among females more than males. This was in agreement with the results of Bernieh B. et al., [12] who documented that in his study (57\%) of the patients were females.

On the other hand, Iseki K. et al., [13] found that women seem to be somewhat protected from developing ESRD.

In the present study, the mean age in patients with ESRD was (52.23 \pm 15.37 years), this was in agreement with Coresh et al., [14] who found that after the age of 30 years, GFR progressively declines at an average rate of $8 \mathrm{~mL} / \mathrm{min} / 1.73 \mathrm{~m}^{2}$ per decade.

On the other hand, Hsu et al., [15] proved that most previous studies of CKD and current recommendations for its management have not distinguished between patients of different ages, and efforts to identify risk factors for progression of CKD have generally focused on patient characteristics other than age.

On the present study, (35.5\%) of the patients were $\mathrm{HCV}$ positive, while $(64.5 \%)$ were $\mathrm{HCV}$ negative.

On the other hand, Alaa Sabry et al., [16] proved that a much higher prevalence $(70.7 \%)$ of $\mathrm{HCV}$ 
viremia was documented among HD patients and found that nosocomial transmission of $\mathrm{HCV}$ infection has been reported to be a considerable route in modern hospital dialysis units. It is known that the prevalence of $\mathrm{HCV}$ is higher among HD patients than the general population with an even higher prevalence as high as $60 \%$ of hepatitis $\mathrm{C}$ viremia reported among our renal transplant recipients. A much higher prevalence $(70.7 \%)$ of $\mathrm{HCV}$ viremia was documented among HD patients and this strongly points to the magnitude of $\mathrm{HCV}$ problem among this selected group of patients.

On the present study, the most common cause of ESRD among those patients was hypertension $(57.75 \%)$ and Diabetes Mellitus (30.25\%), this was in agreement with GL Bakris et al., [17] who found that the frequency of CKD continues to increase worldwide as does the prevalence of ESRD. The most common, but not the only, causes of CKD are hypertension and diabetes. The kidney is both a cause and a victim of hypertension. High blood pressure is a key pathogenic factor that contributes to the deterioration of kidney function. The presence of kidney disease is a common and underappreciated preexisting medical cause of resistant hypertension. Therefore, treatment of hypertension has become the most important intervention in the management of all forms of Chronic Kidney Disease (CKD).

On the present study, the types of anemia in ESRD were normocytic normochromic anemia (69.7\%), hypochromic microcytic anemia $(30.3 \%)$. This was in agreement with George et al., [18] who found that normocytic normochromic anemia is the most common hematological abnormality in chronic renal failure. Erythropoietin deficiency appears to be the major cause of anemia in chronic kidney disease. This type of anemia is characterised by normochromic and normocytic blood cells and hypoplasia of erythroid cells.

Concerning the correlation between PTH and serum $\mathrm{Hb}$ in $\mathrm{HD}$ patients it is known that hyperparathyroidism secondary to CKD is an overproduction of parathyroid hormone caused by several changes that occur in bone and mineral metabolism as a result of decreased kidney function [19]. The first change that usually occurs with decreased kidney function involves the deficiency of activated vitamin $\mathrm{D}$ and an increase in phosphorus excretion by the remaining functional nephrons. Both of these changes stimulate an increase in PTH synthesis and secretion. Secondary hyperparathyroidism due to CKD may also have an unfavorable influence on anemia of uremic patients. There is also indirect evidence of restoration of hematocrit after parathyroidectomy in uremic patients due to restoration of bone marrow space after operation and rise of immunoreactive erythropoietin serum concentration [20].

On the present study (93.5\%) with hyperparathyroidism while, $(5.5 \%)$ with normal PTH and (1\%) with hypoparathyroidism.

This was in agreement with Happy Chutia et al., [20] who found that $95.2 \%$ show hyperparathyroidism and $4.8 \%$ show normal PTH level.

Concerning the correlation between PTH and serum $\mathrm{Hb}$ the present study showed that there was a statistically significant negative correlation between PTH and serum Hb as ( $p$-value 0.001). This was in agreement with Sliem H. et al., [21] who reported statistically significant negative correlation between PTH and serum $\mathrm{Hb}$ among hemodialysis patient $(p=0.001)$. As well Lars P. et al., [22] reported statistically significant negative correlation between PTH and serum $\mathrm{Hb}$ among patients on hemodialysis $(p=0.003)$. While Adhikary P. et al., [23] reported weak negative correlation between $\mathrm{Hb}$ and PTH among hemodialysis patients not reach statistical significance as $(p=0.334)$.

Possible causes of low Hb level with hyperparathyroidism may be due to increased bone marrow fibrosis which may lead to decreased erythropoietin and increased resistance to EPO [21]. Erythropoietin cells express calcitriol receptors which induce proliferation and maturation of erythroid progenitor cells. Therefore, deficiency of calcitriol due to hyperparathyroidism may impair erythropoiesis leading to low $\mathrm{Hb}$ level. An efficient control of PTH hypersecretion is therefore required to achieve abetter management of anemia as well as mineral metabolism in HD patients [23].

Concerning the correlation between reticulocytic count and serum $\mathrm{Hb}$ in HD patients it is known that reticulocytes are young red blood cells that develop from erythroblasts and circulate in the bloodstream for approximately 1-4 days before maturing into erythrocytes. These cells provide a real time assessment of the functional state of erythropoiesis and are thus useful in both diagnosing anemi as and monitoring the bone marrow response to therapy. While reticulocyte count is widely measured in routine laboratory work, the clinical significance of the reticulocyte count in patients on chronic maintenance HD has yet to be clearly delineated. 
On the present study, $(85.3 \%)$ were showing reticulocytosis, while (14.8\%) were normal reticulocytic count. Concerning the correlation between reticulocytic count and serum $\mathrm{Hb}$ the present study showed that there was a statistically significant negative correlation between reticulocytic count and serum $\mathrm{Hb}$ as ( $p$-value 0.003). This was in agreement with Takagi, et al., [24] who found that significant negative correlation between reticulocytic count and serum $\mathrm{Hb}$ as ( $p$-value 0.001 ). Also found that higher incidence of reticulocytosis in patient with ESRD with increase in cardiac mortality rate in patients with reticulocytosis.

There are two hypotheses for the relationship between high reticulocyte count and poor outcome. The first is that the reticulocyte count could be a sensitive marker of tissue hypoxia. Reduction in tissue oxygen tension due to microvascular dysfunction would be expected to lead to the activation of hypoxia inducible transcription factors which in turn might initiate the production of EPO. EPO increases reticulocyte release from the bone marrow and therefore prolongs the maturation time of circulating reticulocytes. This is likely the reason for findings showing a high reticulocyte count [23] The second hypothesis is that reticulocytosis is a result of the accelerated clearance of Red Blood Cells (RBCs). The reticulocytosis found in patients with bad prognosis may reflect the compensatory increase of erythropoiesis against the accelerated clearance of circulating RBCs as result of occult bleeding or impairment of RBC survival including hemolysis, increased eryptosis (apoptotic erythrocyte death), oxidative stress and mechanical pressure might play some roles [23].

There were some limitations to Takagi, et al., [24] study. First, although the study speculated that hemolysis or eryptosis might have been the reason for the increased reticulocyte counts, we did not measure either the serum haptoglobin, phosphatidyl serine positive erythrocyte counts, or spleen size.

Regarding markers of iron profile in patients with anemia it is known that iron deficiency or its limited availability for erythropoiesis, is an important pathogenetic mechanism for the development of renal anemia [25]. The main factor that leads to iron deficiency in dialyzed patients is excessive blood loss during dialysis, especially the significant amount of residual blood that remains inside the dialyzer, dialysis sets, and needles after each hemodialysis session. It is generally accepted that the average annual loss of iron in dialyzed patients is $1.5-2.0 \mathrm{~g}[26]$. The main places where iron is deposited are the reticulo endothelial system of the bone marrow, liver and spleen. Iron is stored as ferritin or hemosiderin [27]. When interpreting the serum ferritin concentrations, it should be remembered that serum ferritin concentrations are increased independently of the amount of iron stores in some conditions, particularly in manifest and latent infections, liver diseases, or malignant tumors [28]. To evaluate the functional iron status, we can use a variety of other laboratory parameters, such as iron plasma concentrations ( $\mathrm{pFe}$ ), transferrin, and transferrin saturation (TSAT) [29]

On the present study, (51\%) were showing decreased T.sat. while, (49\%) were showing normal T.sat. also there was significant positive correlation between T.Sat. and $\mathrm{Hb}$ level ( $p$-value 0.038). This was in agreement with Mohammed Najeeb. et al., [30] who found that transferrin saturation is the most efficient in diagnosis of iron deficiency anemia and is considered to be a more accurate indicator of the metabolic status of iron. Also in agreement with Mahdavi. et al., [31] who found that serum transferrin can more appropriately reflect the amount of body iron supply with significant correlation between T.sat. and $\mathrm{Hb}$ level ( $p$-value 0.001). Low level of transferrin prevents iron transport to the hematopoietic sites and leads to low hemoglobin synthesis as well as hyporesponsiveness to ESA.

On the present study, (56.75\%) were normal ferritin level while, $(37.75 \%)$ show high ferritin level, $(5.5 \%)$ show low ferritin level also show insignificant correlation between serum ferritin and $\mathrm{Hb}$ level this was in agreement with Mahdavi et al., [31] who found that measurement of serum feritin is not an appropriate approach to estimate body iron supply in the presence of inflammation initiated by renal failure.

This result is different than the findings of Rocha et al., [32], who introduced measurement of serum ferritin as a standard way of estimating deposited iron supply in bone marrow in hemodialysis patients. They considered serum ferritin above $500 \mathrm{ng} / \mathrm{ml}$ as cut off level to determine iron deficiency in hemodialysis patients $(p<0.001)$. Due to increase in ferritin activity in acute phase of renal failure, it appears that serum ferritin cut off level for determination of iron deficiency is probably higher in uremic patients than non-uremic people. Nevertheless, this study cannot finally make a direct quantitative correlation between serum ferritin and body iron supply and did not introduce an approach to use this component in estimation of the amount of body iron in hemodi- 
alysis patients. Furthermore, they did not make a comparison between serum ferritin and T.sat.

Regarding correlation between $\mathrm{Hb}$ level and serum albumin in HD patients it is known that inflammatory process has a substantial contribution in the development of anemia in chronic hemodialysis patients through unresponsiveness to Erythropoietin Stimulating Agents (ESA). Several markers including serum C-Reactive Protein (CRP), Erythrocyte Sedimentation Rate (ESR) and serum albumin are considered as measures of inflammation and are usually used for the assessment of inflammatory state and prediction of treatment response. Among the parameters of inflammation, low serum albumin is of particular importance, because it is a reflection of nutritional status and inflammation as well as a marker of protein energy wasting and a component of MalnutritionInflammation Complex (MIC) [32]

On the present study (53.5\%) with hypoalbuminemia while, $(46.5 \%)$ with normal albumin level. This was in agreement with Heidari B [33] who found that $72 \%$ of the patients with anemia show hypoalbuminemia and $28 \%$ show normal albumin level. Concerning the correlation between serum albumin and serum $\mathrm{Hb}$ the present study showed that there was a statistically significant negative correlation between serum albumin and serum $\mathrm{Hb}$ as ( $p$-value 0.019). This was in agreement with Heidari B [33]. Who found that significant negative correlation between serum albumin and serum $\mathrm{Hb}$ (p-value 0.005).

Hemodialysis patients with low serum albumin are at greater risk of anemia and the level of serum albumin can be considered as a predictor of treatment response in hemodialysis patients. The relationship between low serum albumin and anemia possibly due to hyporesponsiveness to ESA in hypoalbuminemic patients the mechanism by which inflammation affect erythropoiesis has been explained by the increased levels of cytokines particularly interleukin-1, this cytokine increases production of CRP and reduces serum albumin and transferrin synthesis [227]. The presence of hypoalbuminemia in hemodialysis patients predicted future development of anemia, this issue justifies further consideration in the treatment of anemia in hemodialysis patients who have hypoalbuminemia. In particular, both hypoalbuminemia and anemia are associated with higher morbidity and mortality in hemodialysis patients. Thus presence of low serum albumin in these patients not only reduces ESA response but imposes the at greater risk of morbidity and mortality.
Regarding correlation between Hb level and CRP in HD patients it is known that (CRP) is one of several acute phase proteins generated by the liver in response to infections, inflammatory conditions, cardiovascular and malignant diseases, which are common causes of co morbidity in hemodialysis patients. An elevated concentration of serum CRP is a strong predictor of increased mortality in hemodialysis patients. CRP is associated with resistance to EPO in hemodialysis patients, in accordance with the view that the EPO response may be inhibited by an inflammatory acute phase reaction, mediated by increased cytokine release.

The present study show (53.3\%) with high CRP level while, $(46.8 \%)$ with normal CRP level. This was in agreement with Heidari et al., [33]. Who found that high serum CRP $(>5 \mathrm{mg} / \mathrm{l})$ was found in $(57.5 \%)$ of the patients.

Concerning the correlation between CRP and serum $\mathrm{Hb}$ our study showed that there was a statistically significant negative correlation between $\mathrm{CRP}$ and serum $\mathrm{Hb}$ as ( $p$-value 0.011). This was in agreement with Heidari et al., [33]. Who found that hemoglobin level conversely correlated with serum CRP ( $p$-value 0.001).

Serum CRP concentration does not change with the changes in kidney function but in the early stage of kidney disease, serum CRP may be related to serum albumin levels which is affected by inflammatory response [32]. It appears that elevated serum CRP may be more associated with thrombotic risk rather than the degree of atherosclerosis. Because serum CRP changes in response to the development of cardiovascular complications so it cannot be considered as an independent factor of atherosclerosis. The association between inflammatory markers and cardiovascular events, coronary artery disease and its complications occur with high frequency in patients with ESRD and substantially is contributing to cardiovascular morbidity and mortality in this population. Elevated levels of serum CRP is linked to the development of coronary artery disease even in the absence of dyslipidemia. Serum CRP level measured by conventional method is apredictor of mortality in hemodialysis patients [32]

\section{Conclusion:}

From this study, we concluded that many factors affect anemia in patients with ESRD on regular hemodialysis these factors include malnutrition, inflammation, iron deficiency and hyperparathyroidism. 


\section{Recommendations:}

1- Future studies including larger number of patients and longer duration are required to better clarify the exact factors affecting anemia in chronic hemodialysis patient.

2- Further studies including assessment of level of pre albumin, interleukin 1 and interleukin 6 in serum of hemodialysis patients and correlation with $\mathrm{Hb}$ level.

\section{Acknowledgements:}

We would like to thank all participants who helped during this study.

\section{Conflict of interest: None declared.}

\section{References}

1- SNYDER S. and PENDERGRAPH B.: Detection and evaluation of chronic kidney disease. Am. FAM. Physician., 72: 1723-32, 2005.

2- Kidney Disease Improving Global Outcomes (KDIGO): CKD Work Group. KDIGO Clinical Practice Guideline for the Evaluation and Management of Chronic Kidney Disease. Kidney Internationl Supplement, 3: 1-150, 2013.

3- LEVIN A., THOMPSON C.R., ETHIER J., et al.: Left ventricular mass index increase in early renal disease: Impact of decline in hemoglobin. American Journal of Kidney Diseases, 34 (1): 125-34, 2000.

4- BESARAB A., BOLTON K.W., BROWNE J.K., et al.: The effects of normal as compared with low hematocrit values in patients with cardiac disease who are receiving hemodialysis and epoetin. The New England Journal of Medicine, 339 (9): 584-90, 2004.

5- ECKHARDT K.: Erythropoietin. Oxygen dependent control of erythropoiesis and its failure in renal disease. Nephron., 67: 7-23, 2011.

6- DRÜEKE T.B. and ECKHARDT K.: Does early anemia correction prevent complications of chronic renal failure? Clinical Nephrology, 51 (1): 1-11, 2008.

7- MEHDI U. and TOTO D.: Anemia, diabetes, and chronic kidney disease. Diabetes Care, 32 (7): 1320-6, 2009.

8- FADROWSKI J.J., PIERCE C.B., COLE S.R., et al.: Hemoglobin decline in childrenwith chronic kidney disease: Baseline results from the chronic kidneydisease in children prospective cohort study. Clin. J. Am. Soc. Nephrol., 3: 457-62, 2008.

9- STAUFFER E. and FAN T.: Prevalence of anemia in chronic kidney disease in the United States. Public Library of Science, 9 (1): e84943, 2014.

10- PETOAND MAXIMUS V.: "Aluminium and iron in humans: Bioaccumulation, pathology, and removal." Rejuvenation research, 13.5: 589-98, 2010.

11- GAWEDA A.E., GOLDSMITH L.J. and BRIER M.E.: Iron, inflammation, dialysis adequacy, nutritional status, and hyperparathyroidism modify erythropoietic response. Clin. J. Am. Soc. Nephrol., 5: 576-81, 2010.
12- BERNIEH B., ABOUCHACRA S., BOOBES Y., et al.: Comparison between short- and long-acting erythropoiesis stimulating agents in hemodialysis patients: Target hemoglobin, variability, and outcome. Int. Urol. Nephrol., 46: 453-9, 2014.

13- ZHOU X. and ZHU D.: Synthesis, labeling and bioanalytical applications of a tris (2, 2 '-bipyridyl) ruthenium (II)-based electrochemiluminescence probe. Nature Protocols, 9 (5): 1146-59, 2014.

14- CORESH J., ASTOR B.C., GREENE T., et al.: Prevalence of chronic kidney disease and decreased kidney function in the adult US population: Third National Health and Nutrition Examination Survey. Am. J. Kidney Dis., 41 (1): 1-12, 2003

15- HSU C.Y., McCULLOCH C.E., IRIBARREN C., et al.: Body mass index and risk for end-stage renal disease. Ann. Intern. Med., 144 (1): 21-8, 2006.

16-ALAA SABRY, KHALED EL-DAHSHAN and KHALED MAHMOUD: Effect of hepatitis C virus infection on heamatocrit and hemoglobin level in Egyption hemodialysis patients. Eur. J. Gen. Med., 4 (1): 9-15, 2007.

17- BAKRIS G.L. and RITZ E.: The message for World Kidney Day 2009: hypertension and kidney disease. A marriage that should be prevented Journal of Human Hypertension, 23: 222-5, 2009.

18- GEORGE S.V. and SAILESH K.S.: "A study to assess changes in the hematological profile in chronic kidney disease." The Pharma Innovation, 4.6, Part A, 2016.

19- ISEKI K., ISEKI C., IKEMIYA Y., et al.: Risk of developing end-stage renal disease in a cohort of mass screening. Kidney Int., 49 (3): 800-5, 1996.

20- HAPPY CHUTIA and ALICE ABRAHAM: Association of secondry hyperparathyroidism with hemoglobin level in patients with chronic kidney disease. J. Lab. Physician'sjan.-Jun., 5 (1): 51-4, 2013.

21- SLIEM H., TAWFIK G., MOUSTAFA F., et al.: Relationship of associated secondary hyperparathyroidism to serum fibroblast growth factor-23 in end stage renal disease: A case control study. Indian J. Endocr. Metab., 15: 105-9, 2011.

22- LARS P., NEELKE C., MURIEL P., et al.: Role of residual renal function in phosphate control and anemia management in chronic hemodialysis patients. Clin. J. Am. Soc. Nephrol., 6: 281-9, 2011.

23- ADHIKARY P., POKHREL A., YADAVA K., et al.: Relation between serum intact parathyroid hormone level and hematocrit in chronic kidney disease patients. Kathmandu. Univ. Med. J., 220-3, 2015.

24- TAKAGI C. and ONO K.: "Higher reticulocyte counts are associatedwith higher mortality rates in hemodialysis patients: A retrospective single-center cohort study." Renal Replacement. Therapy, 3.1 4, 2017.

25- MACDOUGALL I.C. and BIRCHER AJ.: "Iron management in chronic kidney disease: Conclusions from a "Kidney Disease: Improving Global Outcomes" (KDIGO) Controversies Conference." Kidney International, 89: 128-39, 2016 
26- SANDRONI S.:"Venous needle dislodgement during hemodialysis: An unresolved risk of catastrophic hemorrhage." Hemodialysis International, 9.1: 102-3, 2005.

27- DENIC S. and AGARWAL M.M.: "Nutritional iron deficiency: An evolutionary perspective." Nutrition, 23.7 603-14, 2007.

28- ADDISON G.M., BEAMISH M.R., HALES C.N., et al.: An immunoradiometric assay for ferritin in the serum of normal subjects and patients with iron deficiency and iron overload. J. Clin. Pathol., 25: 326-9, 2002.

29- FORD B.A., COYNE D.W. and EBY C.S.: Variability of ferritin measurements in chronic kidney disease; implications for iron management. Kidney Int., 75: 104-10, 2009.

30- MOHAMMED NAJEEB AL-HALLAK and WILLIAM NEWMAN: Transferrin Saturation (TS) Is a Surrogate
Marker for Iron Deficiency Anemia (IDA), Blood, 118: 317,2011

31- MAHDAVI M.R.: "Credibility of the measurement of serum ferrtserum ferritin and transferrin receptor as indicators of iron deficiency anemia in hemodialysis patients." Eur. Rev. Med. Pharmacol. Sci., 15.10 115862, 2011.

32- ROCHA L.: "Serum ferritin level remains a reliable marker of bone marrow iron stores evaluated by histomorphometry in hemodialysis patients."Clinical Journal of the American Society of Nephrology, 4.1 105-9, 2009.

33- HEIDARI B. and FAZLI M.R.: "A linear relationship between serum high-sensitive C-reactive protein and hemoglobin in hemodialysis patients. "Clinical and Experimental Nephrology, 19.4 725-31, 2015.

\section{تقييم الآنيميا فى مرضى الفشل الكلوى المزمن الفوى الفوى

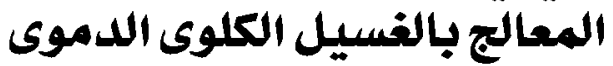 في محافظة الغربية الغلوى}

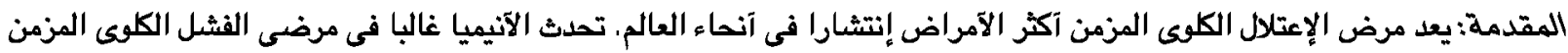

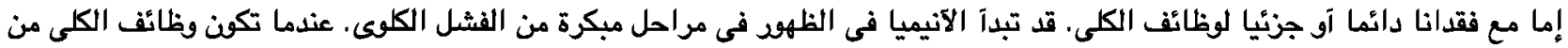

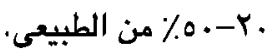

$$
\text { الهدف من البحث: تقييم الآنيميا في مرضى الفثل الكلوى المزمن المعالج بالفسيل الكلوى الدموى في محافظة الفربية. }
$$

المرضى وطرق البحث: يشتمل هذا البحث على · . ع مريض ممن يعانون من وجود آنيميا مع الفشل الكلوى المزمن ويعالجون بالغسيل

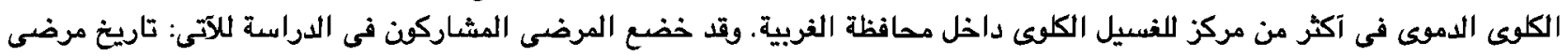

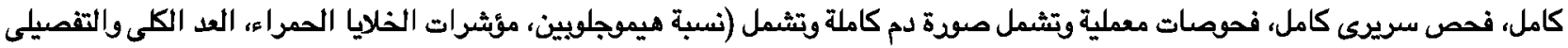

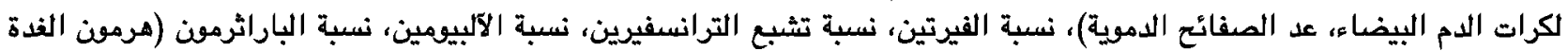

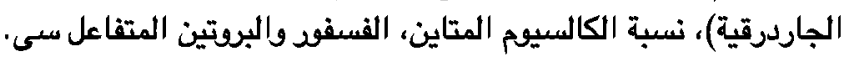

$$
\text { يستبعد من البحث: الإدراج: مرضى الفشل الكلوى المزمن المعالجنف بالغسيل الكلوى الدمىى لفترة آكثر من ثلاثة آشهر. }
$$

النتائج: هناك إرتباط إيجابى ذو دلالة إحصائية بين نسبة الهيموجلوبين ونسبة تشبع الترانسفيرين بالنسبة لمرضى الفشل الكلوى المزمن.

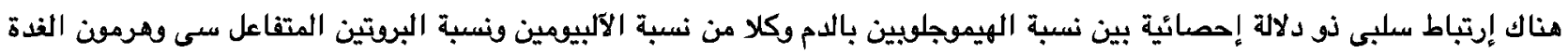

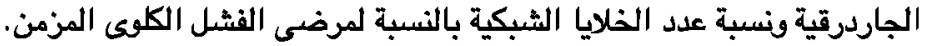

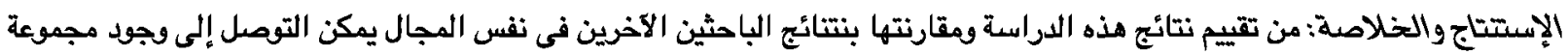

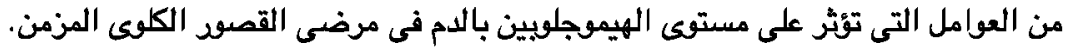

التوصيات: نوصى بإجراء فحص لنسبة الهيموجلوبين ونسبة هرمون الغدة الجاردرقية ونسبة تثبع الترانسفيرين ونسبة عدد الخلايا الثبكية ونسبة الآلبيومين ونسبة البرتين المتفاعل سى لجميع مرضى الفشل الكلوى المزمن. نوصى بإجراء المزيد من الآبحاث مثل نسبة

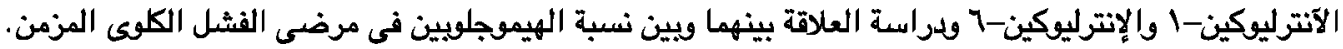

